2-1-2001

\title{
Harmonographs. I. Pendulum design
}

Robert J. Whitaker

Missouri State University

Follow this and additional works at: https://bearworks.missouristate.edu/articles-cnas

\section{Recommended Citation}

Whitaker, Robert J. "Harmonographs. I. pendulum design." American Journal of Physics 69, no. 2 (2001): 162-173.

This article or document was made available through BearWorks, the institutional repository of Missouri State University. The work contained in it may be protected by copyright and require permission of the copyright holder for reuse or redistribution.

For more information, please contact BearWorks@library.missouristate.edu. 


\title{
Harmonographs. I. Pendulum design
}

\author{
Robert J. Whitaker \\ Department of Physics, Astronomy, and Materials Science, Southwest Missouri State University, Springfield, \\ Missouri 65804
}

(Received 3 February 2000; accepted 14 June 2000)

\begin{abstract}
Mechanical devices that undergo various kinds of repetitive motion and which draw the curves produced from this motion are known as "harmonographs." One such class of these devices are those that operate by means of pendulum action. These devices range from modifications of a simple pendulum to various physical and compound pendulums. This paper traces the history of the development of this class of apparatus. (C) 2001 American Association of Physics Teachers.
\end{abstract}

[DOI: $10.1119 / 1.1309521]$

\section{INTRODUCTION}

Devices that are used to investigate nature have been used since ancient times. Objects such as the compass, straight edge, sundial, etc., have been used for mathematical construction or for aids in making observations. From the early seventeenth century, however, a new class of devices began to be developed. Some of these were intended to extend our senses in making observations; others were designed to manipulate nature. A number of these, for example, were invented in the eighteenth century specifically to study electrical phenomena. ${ }^{\text {. }}$

These devices have come to be called "apparatus" or "instruments," and the two terms are often used interchangeably. ${ }^{2}$ Not only were these instruments developed to study nature, but many were also used to entertain and, incidentally, to inform others about nature. Colleges and schools soon began to collect such apparatus in a "philosophical cabinet' for instructional purposes. Several authors have recently discussed the role of instruments in science and have described a number of these, used for a variety of purposes. ${ }^{3}$ All of this led, in turn, to an industry of instrument makers ready to supply such equipment to any who might not want to construct their own. In the nineteenth century popular books began to be illustrated with examples of this apparatus and directions for its use for recreational purposes. ${ }^{4}$ And college and school textbooks appeared which made use of this apparatus in illustrating physical principles. ${ }^{5}$

Among the phenomena that attracted the interest of researchers were those that involved repetitive motion. These occurred in such things as the motion of a pendulum, wheels or gears (as in a clock), as well as the vibrations of the parts which produce sound in a musical instrument. Because of the rapidity of the motion, methods were developed to provide a visual picture of the nature of the vibrations. An important example is that of Chladni, late in the eighteenth century, who used sand to illustrate the patterns formed by a metal plate set in vibration by a violin bow. In addition a number of devices were developed in the nineteenth century to record data automatically for a variety of purposes. ${ }^{6}$

Thomson (Lord Kelvin) and Tait noted in their classic book on mechanics that

Among the most important classes of motions which we have to consider in Natural Philosophy, there is one, namely, Harmonic Motion, which is of such immense use, not only in ordinary kinetics, but in the theories of sound, light, heat, etc., .... ${ }^{7}$

The authors then demonstrated that the projection, on the diameter of a circle, of a point moving uniformly around the circle executed "simple harmonic motion." ${ }^{8}$ If we observe the path traversed by the end of a swinging pendulum, we observe that it traces a straight line, but its motion is identical to the motion of the projection of the point above. If the pendulum (and support) is moved smoothly and perpendicular to the plane of motion of the pendulum, it will trace a sine curve. It is a common exercise in introductory physics textbooks to demonstrate that, for a small amplitude, a pendulum executes simple harmonic motion. ${ }^{9}$

Mechanical devices which execute various forms of harmonic motion and record the curves thus produced have long attracted the attention of scientists, artists, and the general public. Devices of this kind are known as "harmonographs." Some harmonographs have been constructed to demonstrate a particular physical phenomenon. Among these are apparatus in which a pair of moving parts executes simple harmonic motion in mutually perpendicular directions. Others were built for the main purpose of drawing aesthetically pleasing curves. This article will trace the development of that class of harmonographs that make use of pendulum action for their operation. A subsequent article will describe those harmonographs that produce curves through the motion of wheels or gears.

\section{PREVIOUS SURVEYS}

Among the earlier surveys of devices designed to produce and demonstrate harmonic curves was that of J. G. Hagen published in 1879. ${ }^{10}$ Among those Hagen discussed was the "kaleidophone" invented by Wheatstone in 1827. The kaleidophone consists of a thin rod, clamped at one end, which is set in vibration. A silvered, glass bead reflects a beam of light incident upon it. Persistence of vision allows one to observe the path of the bead as it traces curves in space. ${ }^{11} \mathrm{He}$ also noted William Sang's mathematical analysis of it in 1832 and Melde's later contribution in 1862.

He also referred to Lissajous' study of vibrating tuning forks (after whom, he noted, the curves produced were named) and to other vibrating systems. In addition he described the pendulum designed by Blackburn in 1844 (and its modification by William Swan) to trace "Lissajous" figures and the experiments described by Hubert Airy. Finally, he discussed the "harmonograph" designed and sold by Tisley and the "sympalmograph" sold by Browning in London as well as a simplified bifilar, Y-suspended pendulum designed by John Dobson. These will be described below.

In 1881 Joseph Lovering, Hollis Professor at Harvard, wrote on the curves produced by a beam of light reflected from mirrors attached to two tuning forks. This method and 


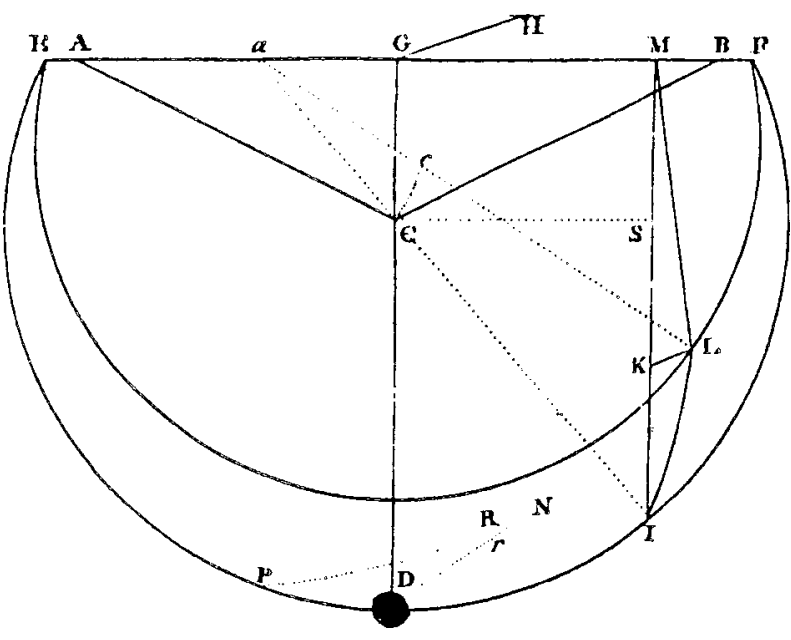

Fig. 1. Bowditch's diagram of the Y-suspended pendulum.

the curves produced, he noted, had been studied by Lissajous and first published by him in 1857 , and he wrote that these curves had come to be known as "Lissajous curves." Lovering also surveyed a number of other devices which produced similar curves, several of which had been described prior to Lissajous' work. ${ }^{12}$ He noted that in 1815 James Dean described a Y-suspended pendulum, and that, in the same year, Nathaniel Bowditch described his experiments with this pendulum and provided a thorough mathematical analysis of its motion. The curves produced are identical to those of Lissajous, and Bowditch's results are the earliest description of those curves. ${ }^{13}$ Bowditch's original figure is given in Fig. 1. Lovering also mentioned Blackburn's Y-suspended pendulum. $^{14}$

In addition Lovering called attention to Wheatstone's ' $k$ aleidophone', and to Sang's analysis of it. He also mentioned the "tonophant" described by Barrett in 1868, and the motion of the end of a vibrating acacia twig described by Hubert Airy in 1871 , each of which operates in a manner similar to that of the kaleidophone and traces similar curves. ${ }^{15}$ Tyndall described a "very efficient apparatus for the compounding of rectangular vibrations" which was also designed by Wheatstone. This is shown in Fig. 2. The vertical rod $(a b)$ is polished at its upper end, and light may be reflected from it. The system of disks and rods causes the steel rod to vibrate in mutually perpendicular directions when the large wheel is turned. ${ }^{16}$

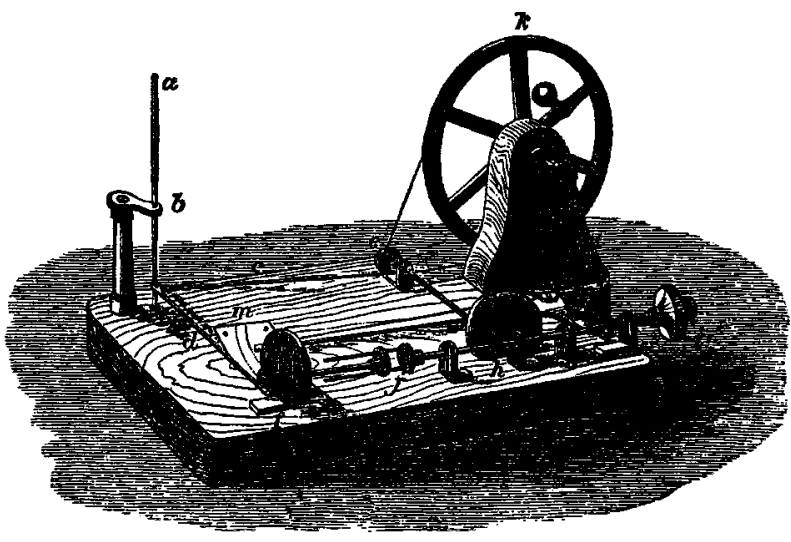

Fig. 2. Wheatstone's compound rectangular vibration apparatus.
The next general survey of curve-producing devices seems to be in the 1909 book, Harmonic Vibrations and Vibration Figures. It was edited by Herbert C. Newton and published by Newton and Co., Scientific Instrument Makers of London. Newton noted that his company undertook its publication since two publishing firms had turned it down for probable lack of profitability of the work. It might be noted that several of the instruments described were, at that time, being manufactured by Newton and Co. Written by several authors, it provides detailed descriptions and illustrations of a number of instruments designed to produce harmonic curves as well as samples of the curves produced. The essay by Charles Benham, "Descriptive and Practical Details as to Harmonographs,' includes mention of Blackburn, Lissajous, Wheatstone, Tisley, and Airy. ${ }^{17}$

The most extensive discussion of harmonic curves and curve machines was provided by William F. Rigge in his book, Harmonic Curves, published in $1926 .{ }^{18}$ In addition to descriptions of various machines Rigge also provided an extensive theoretical description of the curves produced by them. In spite of his attempt at providing a comprehensive list of curve drawing devices, many escaped his notice. However, for some his is the only available description. We will encounter some of these later.

Most recently, Greenslade has encouraged continued interest in the subject through several articles and has provided a valuable perspective on these kinds of apparatus and the curves that they produce. ${ }^{19-22}$ It is my intention to complement his, already firm, foundation on the subject.

\section{Y-SUSPENDED OR “BLACKBURN” PENDULUM}

The motion executed by Wheatstone's kaleidophone, Lissajous' tuning forks, or of a swinging pendulum may be observed visually. The Y-suspended (or Blackburn) pendulum can be adjusted so that it will swing with simple harmonic motion, with a different frequency, in each of two directions simultaneously. This pendulum was modified in such a way that it could also draw the curves produced by this motion by either dropping sand from the pendulum or by a pointer tracing its path in a layer of sand or lamp black below it. Later demonstrators used a spark device to record this path on specially prepared paper. ${ }^{23}$ Airy, in 1871 , provided a detailed description of his attempts at recording, first the motion of the acacia twig with a pencil, and then the motion of the Y-suspended pendulum with a pen. ${ }^{24}$

As early as 1896 Slichter recorded the motion of Blackburn's pendulum by photographing a small electric light attached to it. He also arranged it in such a way as to produce stereoscopic photographs of the curves which could be viewed through a stereoscope. ${ }^{25}$

An interesting variation of the Y-suspended pendulum was designed by John Dobson, S. J. of Stonyhurst College, England. This was described by Hagen, ${ }^{26}$ and Hagen's description was summarized by Rigge. ${ }^{27}$ Rigge referred to this as the "Dobson Duplex Pendulum.' Hagen reported seeing this pendulum in 1877 and that he had then constructed a similar one himself. The principal difference in this from other Y-suspended pendulums is that the suspending cords or wires are bifilar, thus reducing any torsion effects. A diagram is reproduced in Fig. 3.

Rigge described it thus:

Two wires proceed from $O$, where they may be lengthened or shortened, over a fixed pulley $A$. One 


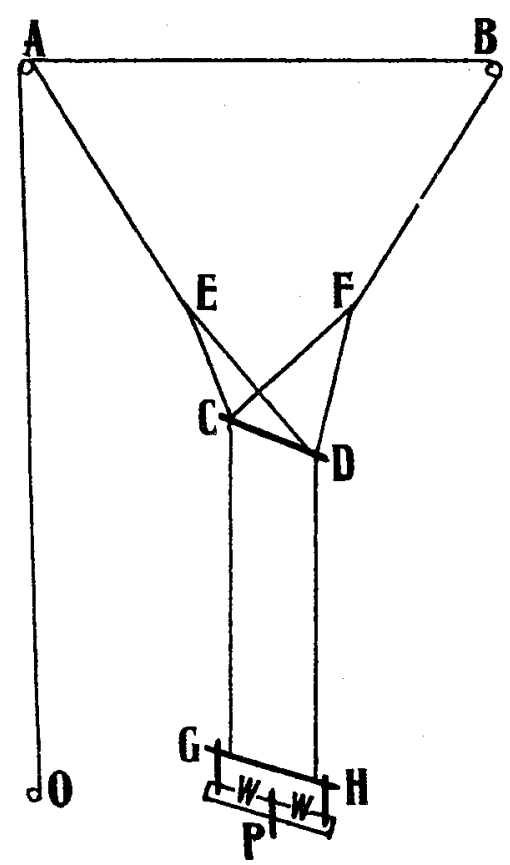

Fig. 3. Dobson's duplex pendulum.

then runs down directly to $E$, and the other over $B$ to $F$. Here both wires become bifilar and run to the rod $C D$, from which two other wires descend to the rod $G H$. At $G$ is a ratchet and crank, so that the wires $C G$ and $D H$ may be wound or unwound on the rod $G H$. This rod $G H$ is secured by standards to a small table, which carries the pen $P$ and heavy weights $W W .^{28}$

Hagen's model had a length of about $3 \mathrm{~m}$ and carried a mass of about $12-15 \mathrm{~kg}$.

Depending upon one's motive for doing the experiment, an advantage (or disadvantage) of a pendulum is its gradual damping. If there were no damping, and if the frequencies of swing in the two directions are properly adjusted, then the pendulum would continue to trace over the same path after the first complete curve had been traced. However, since there is damping, the pendulum continues to trace the same curve but with smaller and smaller amplitude. If the drawing is being produced for aesthetic reasons, this gradual decrease in amplitude produces a variety of interesting pictures. And, since the initial conditions of starting the pendulum are nearly impossible to reproduce exactly, each picture is slightly different.

\section{COMPOUND PENDULUM DESIGNS}

The Y-suspended pendulum is the simplest that one may construct. Since the mass of the supports is negligible with respect to the mass of the bob, this is a simple pendulum. One difficulty in using it is that it requires a suspension of a fairly long cord; and, if its motion is not to damp out too quickly, the mass of the pendulum needs to be fairly large. Tyndall, for example, used a cord $28 \mathrm{ft}$ long in his demonstrations before the Royal Institution. ${ }^{29}$ This difficulty, however, was resolved by other designs of apparatus that make use of two or more separate physical pendulums. One of the first of these, using two pendulums, was described in a short report by S. C. Tisley in 1873 . Tisley noted that the appara-

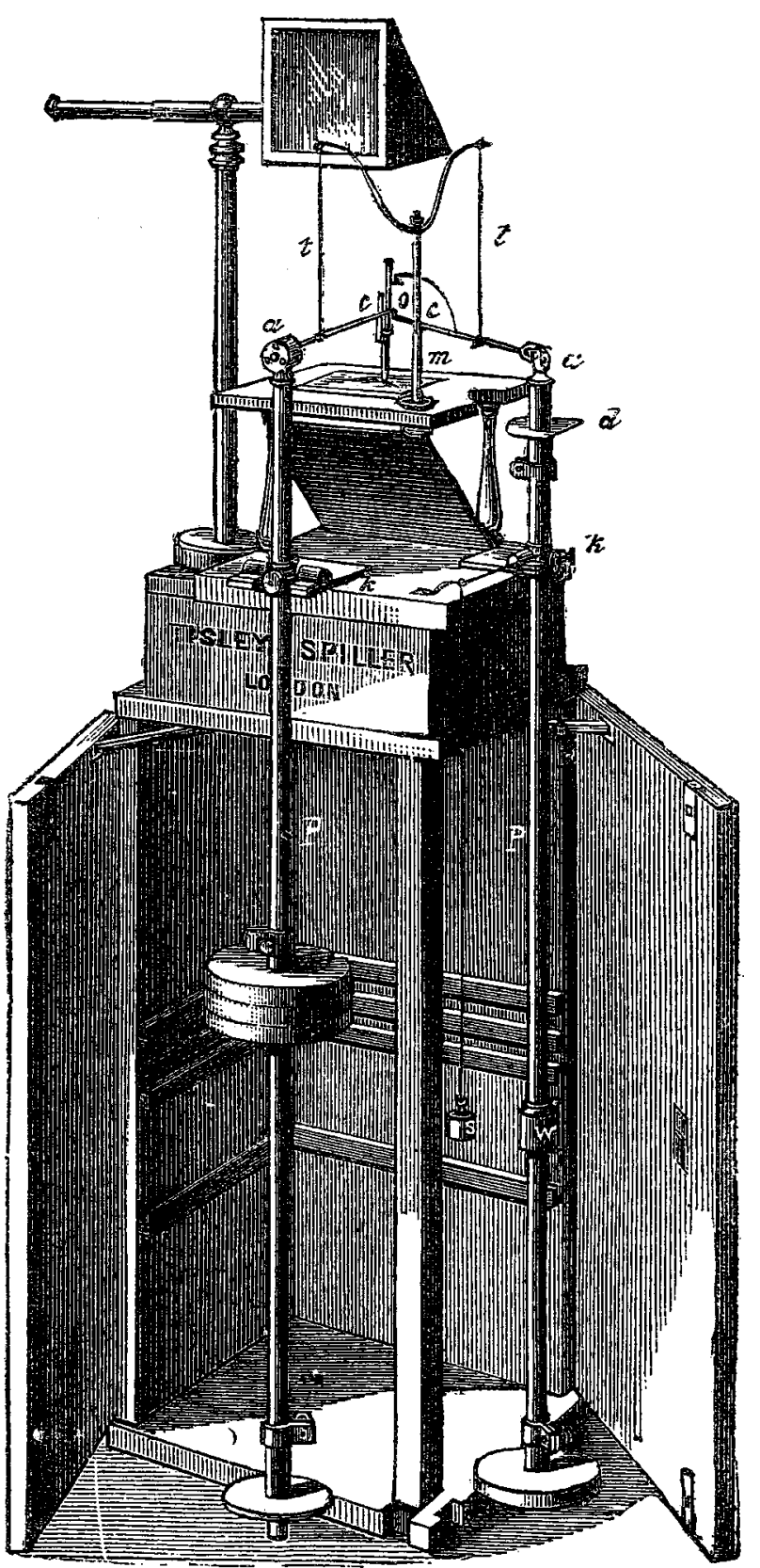

Fig. 4. Tisley's compound pendulum, ca. 1873.

tus " "... was designed for the purpose of recording the figures shown in Lissajous' experiments with tuning forks.", 30

His apparatus (Fig. 4) was made up of two pendulums, consisting of thin rods about $3 \mathrm{ft}$ long, and each fitted with a knife edge about 8 in. below the top of each rod; these were then set to swing at right angles to one another. The top of each rod was fitted with a ball-and-socket joint. A wire arm was screwed into the ball-and-socket, and a pen or other tracer attached at the intersection of the two wires. One pendulum had one sliding pan for holding weights above the point of suspension and another one below it. The second pendulum had two sliding pans, both below the point of suspension. Tisley noted that he used four weights, each about $2 \frac{1}{2} \mathrm{lb}$.

As Tisley described the operation of the apparatus:

When a single weight is placed on each of the bottom pans and properly adjusted, the vibrations of the 
two pendulums being equal, the figure formed by the tracer will be an elliptical spiral, gradually dying out so as to produce a watch-spring-shaped curve. A small sliding weight is attached to the first pendulum and by moving this up or down, the vibrations can be brought perfectly into unison, or thrown slightly out of time, thus producing through the tracer a variety of complicated and interesting figures. The second pan is used for varying the rates of vibration of the two pendulums in certain ratios, so as to produce curves of different characters.

His apparatus was also designed so that:

In the table under the tracer a glass plate is let in, so that, by placing a reflector below and above, a light can be thrown through the object, and a magnified image produced on the screen during its formation; in that case blackened glass and a needle-point for tracer are used.

Thus the table on which the paper (or glass) is placed for tracing the curve is fixed in place, and the pen, fastened at the intersection of the wires attached to the two pendulums, is free to move while the curve is being traced. It may be noted that the end of one of the wires moves at the same frequency as the pendulum to which it is attached and in the same vertical plane; the end of the second wire moves with the frequency and in the plane of the pendulum to which it is attached. The tracing pen then moves, simultaneously, in mutually perpendicular directions in a horizontal plane. The pendulums, being made of rods rather than string or wire, eliminate the problem of torsion that was sometimes encountered with string suspension.

No diagram of the apparatus was reproduced with this brief note. However, the following year a more detailed description was provided in the magazine, Engineering. A picture of his apparatus, manufactured and sold by Tisley \& Spiller, with samples of curves that could be drawn with it was given here. This is the source of Fig. 4. ${ }^{31}$

A modified version of Tisley's compound pendulum (Fig. 5), manufactured by James W. Queen \& Co. of Philadelphia, was offered in the United States in $1879 .{ }^{32}$ It also provided for projection on a screen as the curves were drawn.

In 1878 Tisley described a modification of his double pendulum at a meeting of the Physical Society. The tracing table was mounted on the top of one of the pendulums, and it could be caused to rotate by means of a clockwork mechanism if desired. This “ "... is supported on a kind of gimbal joint formed of two pairs of knife edges at right angles, so arranged that vibration can take place either on one or the other, or the two can be so combined as to give a circular motion; or again, the pendulum can be caused to vibrate in any given plane.' The second pendulum carried an arm, to the other end of which a pencil or pen was attached and positioned over the table. The bob of the second pendulum could be adjusted during its motion by "a very ingenious adjustment.' If two pens are attached, instead of one, and set about $2 \frac{1}{2}$ in. apart, they will draw two curves that are not precisely the same. When these are viewed in a stereoscope, the curve will appear in three dimensions. ${ }^{33}$

Descriptions of Tisley's harmonograph soon began to be found in popular books on science. Pepper, in the fourth edition of his book published in 1877 , provided a clear description and picture of Tisley's apparatus. ${ }^{34}$ This is the same apparatus reproduced in Fig. 4.

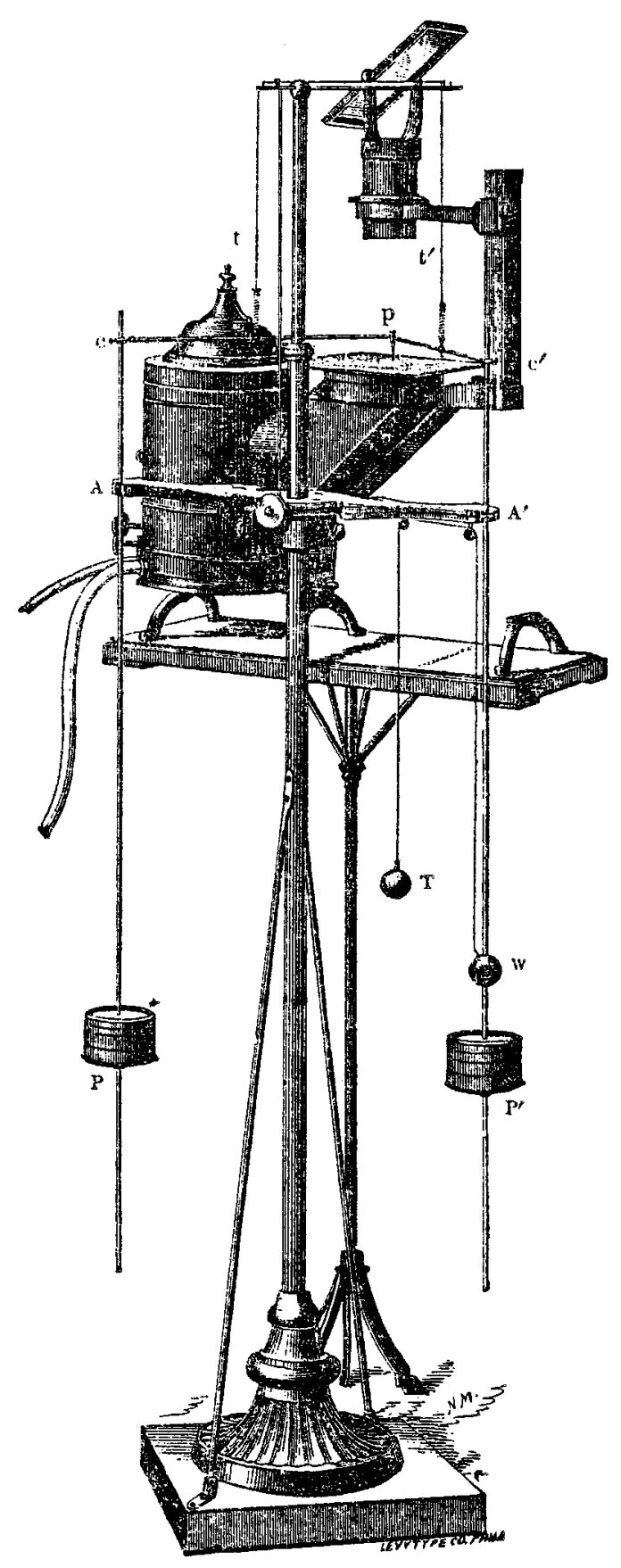

Fig. 5. Queen's modified Tisley compound pendulum, 1879.

Another popular book was Tissandier's Popular Scientific Recreations in Natural Philosophy, Astronomy, Geology, Chemistry, Etc., published both in French and in English translation. In his section on acoustics the author noted: "We will complete the elementary principles of acoustics by describing a very curious apparatus invented by $\mathrm{M}$. Tisley, the HARMONOGRAPH. ...The Harmonograph belongs to mechanics in principle, and to the science of acoustics in application.', 35

Tissandier described the second version of Tisley's harmonograph and provided a picture (Fig. 6). ${ }^{36} \mathrm{He}$ also provided additional information on the means of "ingenious adjustment" referred to by Tisley. He noted that the second pendulum may be adjusted by " ... a small additional weight, the height of which may be exactly regulated by means of a 


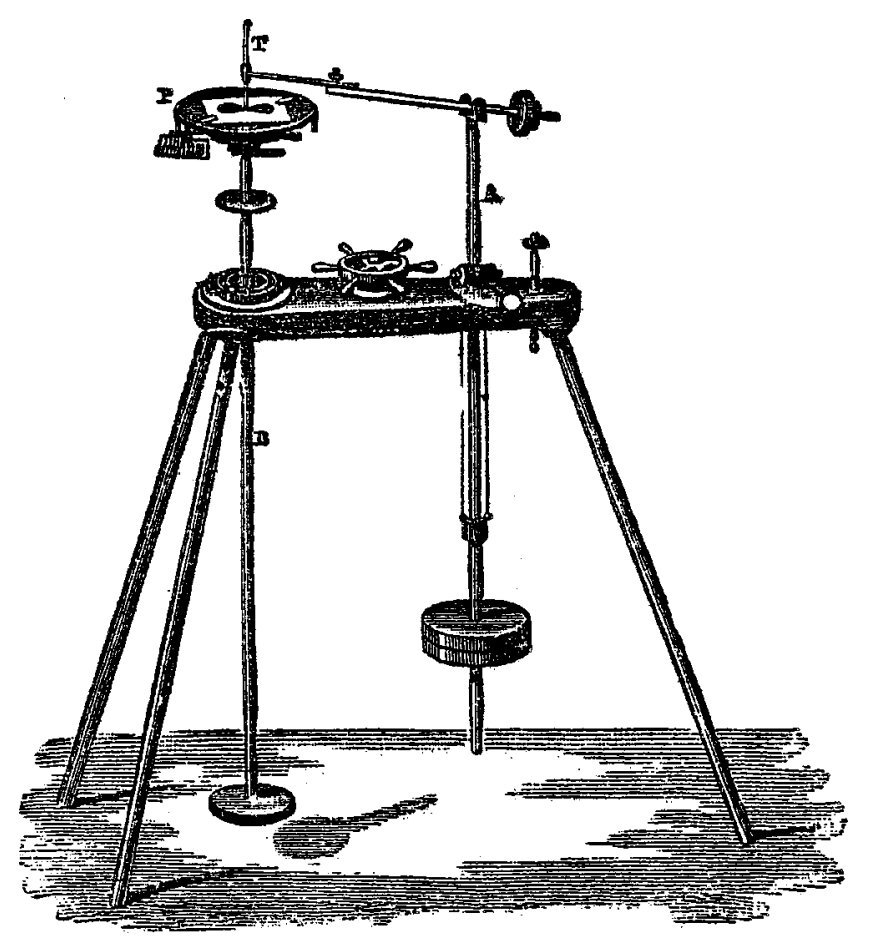

Fig. 6. Tisley's second pendulum design, 1878.

screw and a small windlass." It would seem that this is accomplished by means of the dial in the middle of the stand.

In 1946 Cohen described this same instrument, which was among the apparatus in the Jefferson Physical Laboratory at Harvard, and which had been used by Professor Wallace Clement Sabine at one time. Cohen noted that this harmonograph “... is a beautifully made instrument, varying in several important features from the usual commercially made harmonographs described by Goold and others [Ref. 17].', He also provided information on the dimensions and operation of the apparatus. ${ }^{37}$

The table of the instrument is 16 in. long, and stands 29 in. above the floor. The paper is held in a circular plate, underneath which is a clock mechanism, so that the paper can be made to rotate while a figure is being drawn. The period of the pendulum, on top of which the paper is held, is determined by whether a weight is placed only at the bottom of the pendulum, or at both the bottom and top. ${ }^{38}$

Cohen also provided examples of curves drawn with it.

Herbert Newton, in the introduction to Harmonic Vibrations and Vibration Figures, discussed the operation of a similar, but simplified, version of Tisley's second harmonograph (Fig. 7). The diagram of the apparatus (manufactured by Newton \& Co.) suggests that the means of adjusting the length of the second pendulum during operation was not included in that design. 39

Charles Benham, in this same work, elaborated on the operation of the device, providing extensive information also on the design and construction of pens, inks, paper, cards, and smoked paper for recording. He also provided details on methods of producing stereoscopic designs. He noted that: "In 1874 Mr. S. C. Tisley and Mr. Spiller, of London, showed the harmonograph in practically its present form. This was followed by Mr. Viney's simplification called the Sympalmograph, made by Browning.', 40

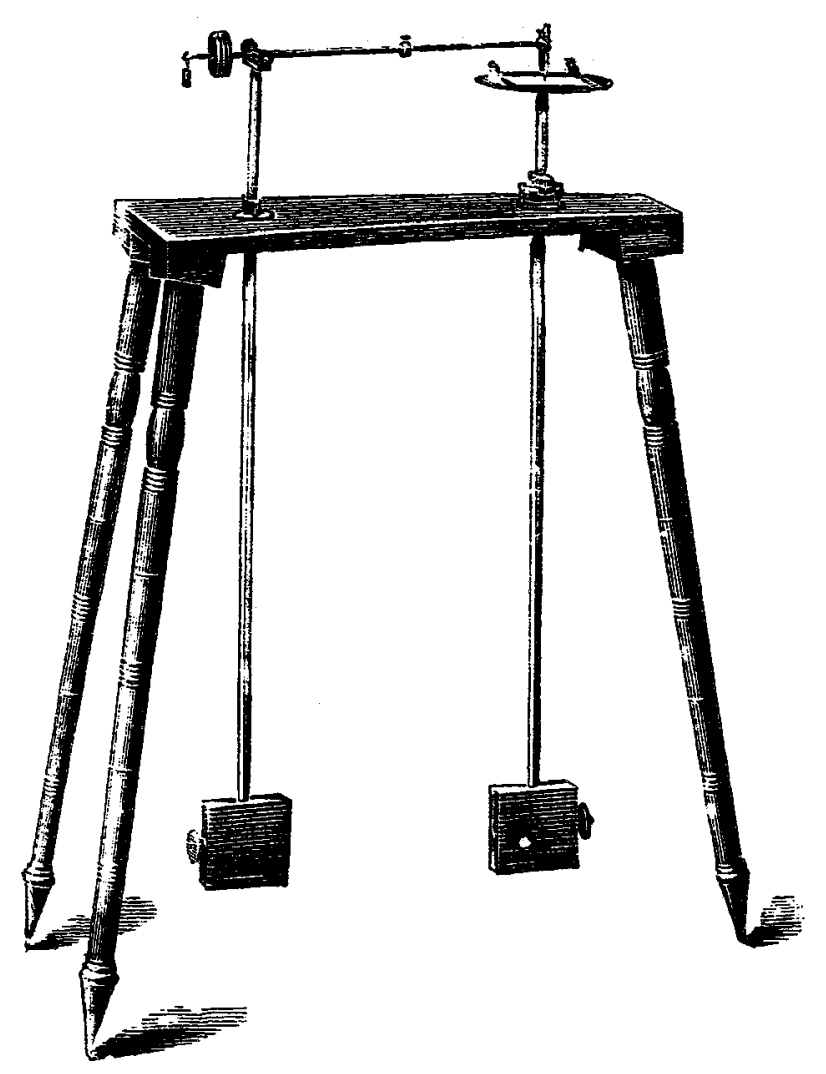

Fig. 7. Newton's modification of Tisley's pendulum.

He also introduced 'Benham's Triple Pendulum.' This is a modification of Tisley's first design; however, instead of the drawing table being fixed, it is mounted on the top of a third pendulum set on a gimbal support. If this pendulum is held still, the apparatus is identical to Tisley's. However, since this pendulum may also be set in motion, the curves are produced from the compounded motion of three pendulums. Benham also provided details on adjusting this apparatus for producing a variety of curves. ${ }^{41}$

The last pendulum design that one finds in the literature is one that might be termed a "double pendulum." One end of a cord or rod is attached to a universal joint; at the other end a mass is attached along with a table, for tracing. A second mass is suspended from the bottom of the table. A pen is attached to one end of a rod, and the other end is attached to a stationary support. The pen then traces a curve on a piece of paper fastened to the table as the system is placed in motion. While the individual designs are somewhat different, the basic concept is the same with each.

One variation of this was exhibited by G. H. Bryan at a meeting of the Mathematical Society in 1894. It was based on one he had seen demonstrated at a meeting of the British Association at Nottingham.

The paper to be drawn on is placed on a heavily weighted board suspended from two points overhead by strings attached to its four corners in such a way that it can swing in any direction without twisting round. From the underside of the board is suspended a weight, thus giving two periods of oscillation. The pen is attached to a triangular framework, hinged to fixed supports, and carefully counterpoised. The pen thus rests gently on the paper, which moves about underneath. ${ }^{42}$ 
A related design was described by Williams in 1902. In place of strings he used a piece of wood- " $2 \frac{1}{2}$ in. broad, 1 in. thick, and 84 in. long' '-fastened to a universal joint at the upper end and to the tracing table at the lower. A second pendulum with a heavy weight was fastened under the table. ${ }^{43}$ Its operation is then as above. Williams noted that the motion of the pendulum produces “ "... a beautiful curve known as a harmonogram, or harmony drawing.' Williams' paper is of interest because it is cited in The Oxford English Dictionary as one source of the term, "harmonogram.', 44

Benham, in 1906, noted that existing harmonographs tended to be cumbersome and required heavy weights. To overcome these problems he introduced a miniature design of the "twin-elliptic pendulum.", 45

A pendulum rod, $\frac{1}{2}$ inch thick, and 20 inches long, is mounted on gimbals at the centre, and passes vertically through a hole of about 2 inches diameter in a firm table. The gimbals are formed by a flat light steel ring, resting on knife edges rising from the table and receiving on its upper surface the knife edges of the pendulum, at right angles to those under the ring. At the top of the pendulum is a flat round table, about 4 inches in diameter. The pendulum weight $(1 \mathrm{lb}$.) slides up and down the lower part of the rod and can be fixed by the perforated nut and screw below it.

A steel wire is attached to the lower end of this rod and the other end of the wire is attached to a second, shorter, rod. A second adjustable weight is attached to this rod. Benham provided more details of construction and operation of this pendulum in his chapter in Harmonic Vibrations...(Fig. 8). ${ }^{46}$ Goold, in this same work, provided additional details on the operation of this pendulum and of his modifications of its design. A commercial version is also illustrated here. ${ }^{47}$

\section{V. 'NONCOMMERCIAL', VARIATIONS}

The compound pendulum devices described above were, at one time, available commercially; and the descriptions by Tisley and by Benham reflect the commercial version. However, it was not long before authors began describing simpler versions that could be constructed by their readers. These might have been addressed to the general reader or to students or teachers in schools or colleges.

Among the earlier of these was a simplified form of Tisley's first apparatus, described by Tissandier, that could be constructed by the reader using only wood and nails (with lead for the weights). A schematic diagram of the completed design is shown in Fig. 9. A "drawing board" was fitted on two sides with pairs of small pieces of wood inset with a small piece of "tin-plate" to form a groove. The pendulums were made of thin lath to which two small pieces of wood were attached; these pieces of wood were fitted with sharp pointed nails and sat on the metal grooves on which the pendulums oscillated. The board was placed on the corner of a table and one pendulum swung parallel to one side and the other parallel to the adjacent side so that the pendulums swung at right angles to one another. A thin piece of wood was loosely attached to the top of each of the pendulums; the opposite end of each was fastened together with a pin so that it was free to rotate. A pen was mounted close to the pin, and paper was placed on the table under the pen. The author used

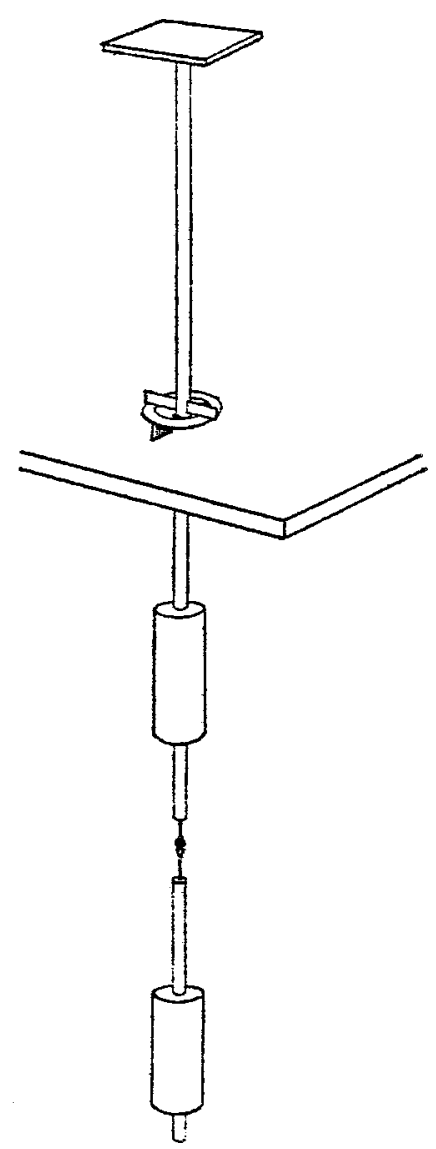

Fig. 8. Benham's twin-elliptic pendulum.

round pieces of lead which encircled each pendulum. The height of each piece could be adjusted and fastened with a screw. ${ }^{48}$

In 1895 Andrew described two devices that he constructed that he called the "pendulograph." Their designs are essentially the same as Tisley's two designs. His motive for con-

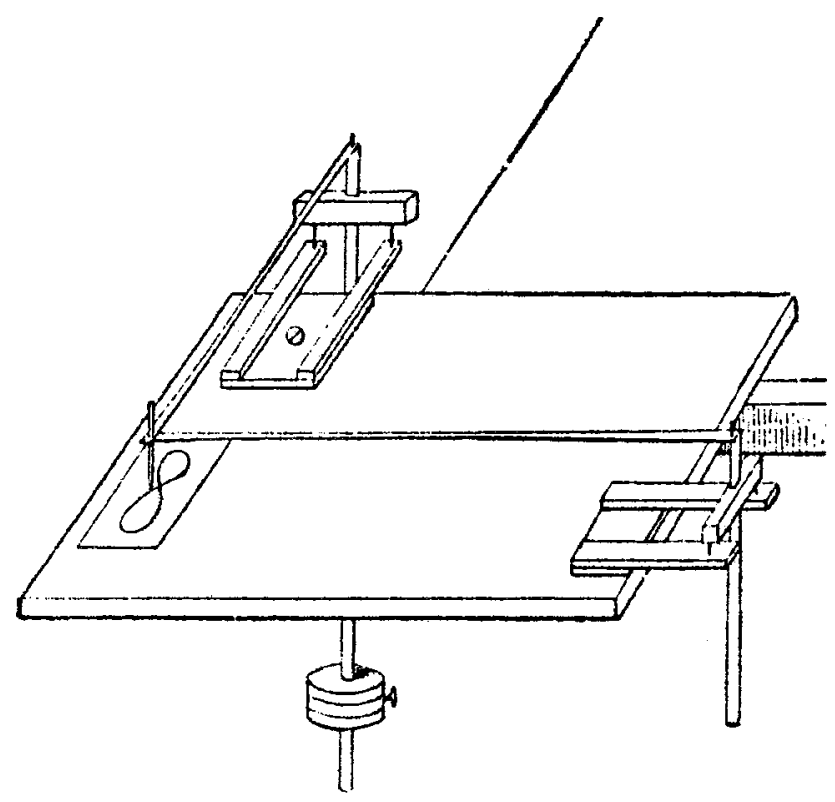

Fig. 9. Tissandier's simplified harmonograph. 
structing his machines was basically aesthetic, and he noted the analogy of the curves produced to musical notes. He concluded with the hope that his

...article should stir up a desire to develop this art of PENDULOGRAPHY, whether as an analogous and illustrative domain of nature in the interest of SCIENCE, or as a new resource of beautiful and very varied designs in the interest of ART.... ${ }^{49}$

Hoferer, in 1899, published the description of a "Quadruple Harmonic-Motion Pendulum', built for public lectures on harmonic motion. ${ }^{50}$ It was designed also to project the curves on a screen while they were being drawn. The description suggests considerable versatility in producing curves of almost any design. Unfortunately, the complexity of the apparatus makes it difficult to obtain a clear idea of its operation from the description and photograph without having it present. It does suggest the continued ingenuity in design of apparatus and interest in the curves that can be produced.

More recently Cundy and Rollett have described a version of the "twin-elliptic pendulum" that can easily be built by the amateur. ${ }^{51}$ They also described a simple harmonograph, similar to that described by Tissandier, as well as the construction of a machine similar to Tisley's second design. This one, they note, requires greater effort and skill in construction, but the results are worth the extra effort. ${ }^{52}$ Greenslade's most recent description of the "double-elliptic harmonograph," based on a design published in 1913 in The Boy Mechanic, provides one further example of a design that can be built by the student or hobbyist. It also shows another appearance of one of these devices in a popular book published early in this century. ${ }^{53}$

Bulman, similarly, offers a comparable design for the amateur that is reasonably simple to construct. ${ }^{54}$ Another variation is given by Stong in his Scientific American column based on designs of Katherine Reed and her father Thomas Reed, which had its beginning in a high school science fair project by Katherine Reed. ${ }^{55}$

Harmonographs for student projects had also been described earlier. Doan described one that follows the design of Tisley, as he noted. This is similar to the design described for construction by Tissandier. ${ }^{56}$ A few years later Plasterer described a similar double pendulum apparatus which could project the curves as they were being drawn. ${ }^{57}$ Both authors note that their apparatus was constructed by students. Hilton described, briefly, several ways of producing curves in what seemed to be a corridor display. ${ }^{58}$

In spite of the general interest in apparatus of this type one finds few cases in which it was a topic for a physics laboratory experiment. The only instance that I have found is in the laboratory manual for introductory physics originally written by Ingersoll. An experiment, 'Lissajou's [sic] Figures,', appeared in the first edition published in 1925 in the section on wave motion and sound. The discussion of the apparatus seemed to refer to the Y-suspended pendulum. ${ }^{59}$ This experiment, as presented in the fifth edition (1942), used a form of a physical pendulum which, from the picture, seemed fairly compact. ${ }^{60}$ It became an electronic experiment, using a cathode ray oscilloscope, in the sixth edition. ${ }^{61}$

One of the motives for the construction of apparatus to draw harmonic curves was aesthetic. The variety and the near symmetry of the curves induced some to build apparatus that would draw them, and most of the designers of appara- tus discussed above have commented on this aspect of their work. Thus, in recent years (1969) a physicist (Tolansky) described two pendulum devices for drawing curves in a journal read, primarily, by artists (Leonardo). He emphasized, in his introduction, that "... it so happens that sophisticated electronics systems cannot create patterns which even remotely compare either in interest or in aesthetic appeal with those that can be formed by quite crude mechanical pendulum devices ...., 62

Tolansky's first design consists of two physical pendulums. One pendulum carries the pen, the second the writing table. Each is balanced on a knife edge similar to Tisley's second design. This differs, however, from Tisley's in that the support for the pendulum carrying the table may be rotated so that the two pendulums no longer swing at right angles to one another. Thus, adjustment of the angle of swing of the second pendulum introduces additional variations in the curves that may be produced. ${ }^{63}$

The basic design of Tolansky's second pendulum is the same as the "twin-elliptic pendulum.', He noted those variables which affect its motion: the weight of the second (lower) bob; the period of the second bob, adjusted through the length of the wire; the phase of perturbation; the amount of damping; and, the geometric form of the perturbation. It is this last variable, the author emphasized, that was the most important; and that no two curves were ever identical. He illustrated the effect of these with reproductions of several curves he had produced. ${ }^{64}$ In his conclusion he reemphasized his reasons for building his apparatus.

My object here has been to put operations on a rational basis to guide any art designer who might wish to operate such a device. One further point is really worthy of mention. The growth of the pattern, which establishes its main character in a few seconds, is fascinating to watch. ${ }^{65}$

Romer has also described a double pendulum apparatus (similar to Tisley's first design) set up as an interactive corridor display, which emphasized the artistic aspects of the curves drawn. ${ }^{66} \mathrm{He}$ observed that

... this apparatus can be used to produce a wide variety of designs which seem to have considerable aesthetic appeal to many people. We have found it very valuable, both in stimulating an interest in the simple physics on which it is based and perhaps more honestly, simply as an "art machine.' If nothing else, it serves to generate some heated discussions as to what is art and what is not. ${ }^{67}$

The author provided useful suggestions for the operation of the apparatus and suggestions for more advanced studies possible with it.

Perhaps the most detailed machine drawings for constructing a double pendulum system appeared in the volume, Physics Demonstration Experiments, sponsored by AAPT and published in $1970 .{ }^{68}$ The points of oscillation appear to be fairly delicate; it might be difficult to maintain this apparatus for general student use.

One cannot leave this subject, however, without mention of the wonderful satire of "big" science and the "nationalistic" arguments for its support reprinted by Weber, and with a proposal for a greatly enlarged pendulum harmonograph as its subject. The proposal began:

Art today is on the threshold of far reaching dis- 
coveries which will come to fruition with a new theory of the nature of art and the fundamental processes of artistic expression. Before the advent of the Harmonic Pendulum, art was a haphazard, subjective and often highly emotional act on the part of the artist, but now we possess a powerful tool for the investigation of the very nature of Art itself. ${ }^{69}$

"Progress" in the field will require new and expanded facilities, according to the proponents, in order to build a pendulum with greatly increased length and mass; and this construction will provide significant new employment. The reader is referred to the original for details of how this will be accomplished.

\section{DISCUSSION AND CONCLUSIONS}

Apparatus makers at the end of the nineteenth and the beginning of the twentieth centuries manufactured a variety of harmonographs. Cohen observed that the one in the collection at Harvard was "beautifully made." This seems to be the only commercially sold pendulum harmonograph that I have found described in the literature that was in a college or university collection. How many institutions have one that "no one knows what it is?" (Indeed, what other "antique", apparatus might fit that description? $)^{70}$

In spite of the apparent simplicity of recording the path of a pendulum, a variety of designs of pendulum harmonographs has been traced. Whether manufactured by a professional instrument maker or built by a school student, each device demonstrates an interesting variation on a general design. Since the design of the Y-supported pendulum is such that the mass of the cords may be neglected, each length may be treated as a simple pendulum, and the period of each may be calculated. However, when we look at the other designs, each pendulum is a physical pendulum made up of several parts. Thus the moment of inertia of each part must-in principle-be determined in order to calculate its period. ${ }^{71}$ That this was not done for any of the harmonographs described above is suggestive. We find, instead, phrases such as: "'properly adjusted,' "'ingenious adjustment,' and ' adjust the length." The period of each pendulum was found by trial and error. The operation of the apparatus, as well as the resulting curves, is as much an art as a science. And, small adjustments in the apparatus can produce large differences in the resulting curves.

That class of harmonographs constructed of gears and pulleys will be discussed in a subsequent paper. It will be seen that apparatus of this kind can be constructed so that one can set it to control the particular curves that it draws.

\section{ACKNOWLEDGMENTS}

The author is indebted to the staff of the Interlibrary Loan Department of the Duane G. Meyer Library for their diligent efforts in obtaining many of the references used in the preparation of this article. He is also pleased to acknowledge the efforts of the Reinert/Alumni Library at Creighton University for similar assistance. He also extends his appreciation to the Graduate College and the Faculty Leave Committee of Southwest Missouri State University for the grant of a Summer Faculty Fellowship to provide the time for the writing of this paper. Thomas B. Greenslade, Jr. provided a number of valuable suggestions to an earlier draft of this paper. I have attempted to acknowledge these where they occur. Rev. C. M. Wagener, S. J. of the Creighton University Department of Physics provided support and encouragement for this project for many years. This short statement is inadequate to express my appreciation. Fr. Wagener passed away 28 April 2000. This paper is dedicated to his memory.

\section{APPENDIX A: WHY LISSAJOUS' CURVES?}

When Lovering conducted his survey of the history of "Lissajous Curves", in 1881, he concluded with the comment:

I have now traced the mathematical analysis and the experimental illustration of the Lissajous curves from France to Great Britain, and thence, across the ocean, to their home in Salem, Massachusetts. The so-called Lissajous curves are the Bowditch curves .... They will continue, probably, to be called the Lissajous curves. But their history should be known, and will be known; though it is not necessary for the reputation of the self-taught mathematician, Dr. Nathaniel Bowditch. ${ }^{72}$

Writing in 1881 Lovering seems to have missed the series of articles on the subject published in 1873 by Augusto Righi in Bologna. Righi's biographer noted that his interest in experimental devices as well as his approach to the analysis of data "... led to an important analytical paper on the composition of vibrational motion (1873), described by Lissajous some months before." 73 In this series of papers Righi also analyzed those curves produced by two mutually perpendicular vibrations in two dimensions and extended his analysis to vibrations in three dimensions. ${ }^{74}$

Nature, in 1898, published a description of an apparatus reported by Righi for displaying the resultant of two oscillations:

One of the two pendulums used consists of a leaden ring containing a cup filled with white sand, suspended by cords, and the length of this pendulum can be altered by raising or lowering a sliding piece. The second pendulum carries a table on which a piece of black paper is slowly drawn by clockwork in a direction perpendicular to the plane of vibration, and the sand escaping from a hole in the cup of the upper pendulum traces out the vibration curves on the paper, the thickness of the line of sand being greatest where the motion is slowest and vice versa. $^{75}$

Tyndall repeated Lissajous' experiments in his lectures on sound, and demonstrated the curves that resulted from this and by other methods. He referred to them only as "rectangular vibrations"; he did not use the term "Lissajous' curves.' "He also noted that "Mr. Sang, of Edinburgh, was, I believe, the first to treat this subject analytically.", 76

Poynting and Thomson described the Y-suspended pendulum, a simplified compound-pendulum harmonograph, and Wheatstone's kaleidophone as all producing similar figures. ${ }^{77}$ They then noted that "Lissajous obtained similar figures by compounding the vibrations of two tuning-forks moving in perpendicular planes.' They proceeded to note that the resulting image describes "Lissajous' figures.", 78 The authors did not, however, refer to Bowditch.

Arthur Taber Jones, in his textbook on sound published in 
1937, also traced the history of the curves formed by the combination of two simple harmonic motions in mutually perpendicular directions, and he documented Bowditch's description of these curves in 1815 . He also noted Lissajous' later contribution using tuning forks. He observed: "Lissajous made a considerable study of the patterns that can be obtained, and they are now usually called Lissajous figures.', 79

Tolansky, in the introduction to his paper, pointed out that the patterns produced by mutually perpendicular harmonic motions had been described by Bowditch in 1815 and, later, described by Lissajous in $1857 .{ }^{80}$

Among his extensive list of different curves, Lawrence listed: "Bowditch Curve (Bowditch, 1815). The Bowditch curve (or the curve of Lissajous) is defined ...." 81 Dewdney, referring to Lawrence, notes "... a class of forms called the Bowditch curves, or Lissajous figures, ...., 82 Sydenham listed "Lissajous" figures as being first proposed by Bowditch in 1815 and "reinvented" by Lissajous in $1855 .^{83}$ More recently, Greenslade has noted Bowditch's priority; ${ }^{84}$ and Crowell has provided further details on the work of Dean and of Bowditch. ${ }^{85}$

Thus it is clear that many authors have recognized that a number of researchers had designed various apparatus that generated these curves. Some of these authors also note that, in addition to Bowditch, others (such as Sang) developed analyses that led to the same equations. They have also recognized the priority of Bowditch in first describing these curves and that some (such as Lawrence) refer to them as "'Bowditch curves.' What is not clear, however, is when and why the appellation, "Lissajous' curves" apparently became the standard term. Some terms, which have entered the technical language, have a clear genesis. Unfortunately, this does not seem to be one of them.

\section{APPENDIX B: THE MATHEMATICS OF "LISSAJOUS' CURVES"}

The mathematical analysis of those curves that have come to be called "Lissajous' curves" (or figures) began, as noted above, with Bowditch; and Sang produced an identical analysis in his study of Wheatstone's kaleidophone. The method of making the rapidly vibrating tuning fork "visible" was a major contribution of Lissajous. His published accounts of his researches began in $1855 ;{ }^{86}$ and a lengthy $(85$ pages) account of his experiments and analysis appeared in $1857 .{ }^{87}$ His work quickly became known, and he lectured on the subject at the Royal Institution in $1857 .{ }^{88} \mathrm{He}$ was awarded the Lacaze Prize by his French colleagues in $1874 .^{89}$

Simultaneous analysis of the "universal kaleidophone," by Melde ${ }^{90}$ and by Lippich, ${ }^{91}$ which produced the same curves, was published in 1862. And Righi, similarly, described these curves in 1873 , extending his analysis to three dimensions. $^{92}$

"Lissajous' curves"' and their means of production has been a topic in a number of textbooks-particularly on acoustics-over the years. It is not my intention to attempt to repeat these analyses here, nor to review all of the instances of their appearance. In addition to references above, the following are offered as providing useful insights to the subject: Rayleigh; ${ }^{93}$ French; ${ }^{94}$ Fahy and Karioris; ${ }^{95}$ Karioris $;{ }^{96}$ Smith $;{ }^{97} \mathrm{Wu}$ and Tsai $;{ }^{98}$ Greenslade $;{ }^{99}$ and Tong. ${ }^{100}$
${ }^{1}$ J. L. Heilbron, Electricity in the 17th and 18th Centuries: A Study in Early Modern Physics (University of California Press, Berkeley, 1979; Dover, Mineola, NY, 1999); Elements of Early Modern Physics (University of California Press, Berkeley, 1982).

${ }^{2}$ Deborah Jean Warner, "What is a scientific instrument, when did it become one, and why?," Br. J. Hist. Sci. 23, 83-93 (1990).

${ }^{3}$ See particularly W. D. Hackmann, "Scientific instruments: Models of brass and aids to discovery," in The Uses of Experiment: Studies in the Natural Sciences, edited by David Gooding, Trevor Pinch, and Simon Schaffer (Cambridge U.P., Cambridge and New York, 1989), pp. 31-65; Making Instruments Count: Essays on Historical Scientific Instruments Presented to Gerard L'Estrange Turner, edited by R. G. W. Anderson, J. A. Bennett, and W. F. Ryan (Variorum, Aldershot, Hampshire, UK and Brookfield, VT, 1993); Thomas L. Hankins and Robert J. Silverman, Instruments and the Imagination (Princeton U.P., Princeton, 1995).

${ }^{4}$ Gerard L'E. Turner, "Scientific toys," Br. J. Hist. Sci. 20, 377-398 (1987). An entertaining selection of examples from the popular nineteenth century magazine, The English Mechanic, may also be found in Alan Sutton, A Victorian World of Science (Adam Hilger, Bristol and Boston, 1986); see particularly Chap. 3, "Philosophical Amusements, Pastimes and Hobbies."

${ }^{5}$ Greenslade has provided an extensive collection of examples from these textbooks in his series of articles in The Physics Teacher. A complete list of these (to 1994) may be found in A. P. French and Thomas B. Greenslade, Jr., Physics History from AAPT Journals II (AAPT, College Park, MD, 1995), pp. 241-242. Other references to nineteenth century apparatus may also be found here.

${ }^{6}$ Reference 3, Hankins and Silverman, pp. 113-147. See also the citations in their Ref. 6, p. 260.

${ }^{7}$ Sir William Thomson (Lord Kelvin) and Peter Guthrie Tait, Treatise on Natural Philosophy (Cambridge U.P., London, 1912), Pt. I, Rev. ed.; Principles of Mechanics and Dynamics (Dover, New York, 1962), pp. 37-38. ${ }^{8}$ Reference 7, p. 38, The Oxford English Dictionary (Clarendon, Oxford, 1989), Vol. VI, 2nd ed., p. 1123, attributes the 1867 edition of this work as the first reference to this term.

${ }^{9}$ David Halliday, Robert Resnick, and Jearl Walker, Fundamental of Physics: Extended with Modern Physics (Wiley, New York, 1993), 4th ed., pp. 390-391.

${ }^{10}$ S. J. Hagen, “Ueber die Verwendung des Pendels zur graphischen Darstellung der Stimmgabelcurven,'” Z. Math. Phys. 24, 285-303 (1879).

${ }^{11}$ The description and operation of the kaleidophone has recently been provided in Thomas B. Greenslade, Jr., "19th Century textbook illustrationsLI: The kaleidophone," Phys. Teach. 30, 38-39 (1992).

${ }^{12}$ Joseph Lovering, "Anticipation of the Lissajous curves," Proc. Am. Acad. Arts Sci. 16 (new series 8), 292-298 (1881).

${ }^{13}$ James Dean, "Investigation of the apparent motion of the Earth viewed from the moon, arising from the moon's librations," Mem. Am. Acad. Arts Sci. 3, 241-245 (1815); American Periodical Series (II), Reel 363 (Microfilm); Nathaniel Bowditch, "On the motion of a pendulum suspended from two points," Mem. Am. Acad. Arts Sci. 3, 413-436 (1815); American Periodical Series (II), Reel 363 (Microfilm). His figure appeared in Plate III. The work of Dean and Bowditch has been described, more recently, in A. D. Crowell, "Motion of the Earth as viewed from the moon and the Y-suspended pendulum,"' Am. J. Phys. 49, 452-454 (1981).

${ }^{14}$ For further details see Robert J. Whitaker, "A note on the Blackburn pendulum," Am. J. Phys. 59, 330-333 (1991).

${ }^{15} \mathrm{~A}$ further survey of the kaleidophone and similarly operating devices may be found in Robert J. Whitaker, "The Wheatstone kaleidophone," Am. J. Phys. 61, 722-728 (1993). The vibrations of an automobile whip antenna are identical to those of the kaleidophone. These have been discussed in: Clarence H. Annett, " Observation of the first overtone vibrational mode in an automobile whip antenna," ibid. 47, 820-822 (1979); Lawrence W. Panek, "Demonstration of the first overtone transverse vibrational mode in a stiff solid bar,"' ibid. 48, 786 (1980); Ronald Newburgh and G. Alexander Newburgh, "Finding the equation for a vibrating car antenna," Phys. Teach. 38, 31-34 (2000). I am indebted to Thomas B. Greenslade, Jr. for calling my attention to these earlier references.

${ }^{16}$ John Tyndall, Sound (Appleton, New York and London, 1903), 3rd ed., pp. 420-422. A nearly identical apparatus was listed in Rudolph König, Catalogue des Appareils d'Acoustique (P. Mouillot, Paris, 1889), Cat. No. 266, 200 fr. Thomas B Greenslade, Jr. kindly called my attention to this reference. More on the apparatus manufactured by [Karl] Rudolph König may be found in Thomas B. Greenslade, Jr., "The acoustical apparatus of Rudolph Koenig,', Phys. Teach. 30, 518-524 (1992), and the references 
therein. Acoustical papers from various periodicals were reprinted in $\mathrm{Ru}-$ dolph Kœnig, Quelques Expériences d'Acoustique (A. Lahure, Paris, 1882). (In the spelling of König's name I have attempted to be consistent with the original.)

${ }^{17}$ Joseph Goold, Charles E. Benham, Richard Kerr, and L. R. Wilberforce, Harmonic Vibrations and Vibration Figures, edited by Herbert C. Newton (Newton \& Co., Scientific Instrument Makers, London, 1909); Benham, pp. 29-33. A list of apparatus available, with prices, is included at the end of the book. The book was reviewed by C. V. Boys, 'Lissajous's figures,' Nature (London) 82, 96 (25 November 1909). King and Millburn write about the firm: "[John] Newton was originally associated with William Palmer, a land-surveyor and cartographer ... . His business later became successively Newton and Son and J. and W. Newton, and after his death, Newton and Co., 3 Fleet Street.' See Henry C. King and John R. Millburn, Geared to the Stars: The Evolution of Planetariums, Orreries, and Astronomical Clocks (University of Toronto Press, Toronto and Buffalo, 1978), p. 210.

${ }^{18}$ William F. Rigge, S. J., Harmonic Curves (The Creighton U.P., Omaha, NE, 1926).

${ }^{19}$ Thomas B. Greenslade, Jr., "'19th Century textbook illustrations. XXVII. Harmonographs,', Phys. Teach. 17, 256-258 (1979).

${ }^{20}$ Reference 11 .

${ }^{21}$ Thomas B. Greenslade, Jr., "All about Lissajous figures," Phys. Teach. 31, 364-370 (1993).

${ }^{22}$ Thomas B. Greenslade, Jr., "The double-elliptic harmonograph,' Phys. Teach. 36, 90-91 (1998).

${ }^{23}$ Reference 14 , and references cited therein.

${ }^{24}$ Hubert Airy, "'Pendulum autographs. I,' Nature (London) 4, 310-313 (17 August 1871); "Pendulum autographs. II,' 4, 370-372 (7 September 1871). Airy provides much detail regarding the adjustments of the pendulum cords, the mass of the pendulum, and the design of the pen and ink for recording the motion of the pendulum.

${ }^{25}$ Charles S. Slichter, "Harmonic curves of three frequencies," Trans. Wisc. Acad. Sci. 11, 449-451 (plus plates) (1896-97). An abstract of Slichter's work appeared in Nature (London) 57, 323 (3 February 1898). It noted: "The tracing of the pretty curves formed by compounding pendulum vibrations of different periods is a fascinating pastime of which we were beginning to believe the resources were pretty well exhausted.' A mathematical discussion of Slichter's paper was published by a senior student at the University of Wisconsin: Elting H. Comstock, "The real singularities of harmonic curves of three frequencies,' Trans. Wisc. Acad. Sci. 11, 457-464 (1896-97). Hales, unaware of Slichter's paper at the time he performed the experiment, described a similar photographic method in 1945. Wayne B. Hales, 'Recording Lissajous figures,' J. Acoust. Soc. Am. 16, 137-146 (January, 1945). Hales also summarized the work of his predecessors as discussed above. He used a 12-lb ball suspended from a principal length of $325 \mathrm{~cm}$. A similar method was also described by C. L. Stong, "The amateur scientist," Sci. Am. 229, 107-109 (August, 1973).

${ }^{26}$ Reference 10, pp. 287; 297-299. Hagen emphasized the advantages of Dobson's pendulum were its simplicity of construction and its cost. Tisley's commercial harmonograph was listed at 400 Marks and Browning's version was 70 Marks.

${ }^{27}$ Reference 18 , pp. $68-71$. Rigge's brief, previous discussion of pendulum devices is limited and is restricted to references given in Hagen's paper. It should be noted that Hagen, Rigge's former professor at Georgetown University and who, in 1926, was Director of the Vatican Observatory, had encouraged Rigge to write his book. Rigge is the only author I have found who cites Hagen's paper. Biographical information on Hagen may be found in: Alice Farnsworth, "Rev. John G. Hagen, S. J., 1847-1930," Publ. Astron. Soc. Pac. 42, 281-284 (October, 1930); J. Stein, “Johann Georg Hagen, S. J.,' Pop. Astron. 39, 8-14 (January, 1931).

${ }^{28}$ Reference 18 , pp. 68-69.

${ }^{29}$ Reference 16, pp. 413-415.

${ }^{30}$ S. C. Tisley, "On a compound-pendulum apparatus,' Rept. Br. Assn. Adv. Sci. 43, 48 (1873).

31 “Tisley's compound pendulum,' Engineering 17, 101-102 (6 February 1874). Tyndall provided a brief description of Tisley's apparatus in his lectures on sound. He observed that " ... the most instructive apparatus for the compounding of rectangular vibrations is that of Mr. Tisley,' Reference 16, p. 420. The advertising section of Nature is a useful source of information on instrument makers and some of their products. The firm of "Tisley and Spiller" first published an announcement of their anticipated opening in October, 1872: "Tisley and Spiller, Scientific Instrument Makers, 172 Brompton Road, S.W. Will shortly open the above premises for the Manufacture and Sale of Philosophical Apparatus, with the most modern Improvements in Electricity, Magnetism, Spectrum Analysis, \&c." Nature (London) 6, ci (24 October 1872). And in December they announced that they "Have opened the above premises for the Manufacture and Sale ... .' Nature (London) 7, xx (5 December 1872). In January, 1874 the first announcements were made regarding Tisley's pendulum: "Tisley's Compound Pendulum Apparatus, With Pens, Ink, \&c, for drawing Lissajous' Curves (as produced by Wheatstone's Kaleidophone) on Cards, or on blackened Glass for the Lantern, and packed in strong Deal Cabinet ( $3 \mathrm{ft} .1 \mathrm{ft} .1 \mathrm{ft}$.) which also serves as a Stand for the instrument to work on.’' The price was given as $£ 10$. Also advertised were attachments for projection, specimen curves, and "Educational Set of Acoustic Apparatus, For performing many of the experiments, included in the course of Lectures recently given by Dr. Tyndall at the Royal Institution,', The firm is now referred to as "Tisley and Spiller, Opticians, etc." Nature (London) 9, xci (22 January 1874). In March the wording was changed to announce: “Tisley's Pendulum Apparatus, With Tracer, \&c., for drawing Lissajous' Curves on Cards, or blackened Glass for the Lantern;... .' Nature (London) 9, clx (19 March 1874). By 3 May 1877 the advertisement, in addition to advertising 'Prof. Dewar's New Electrometer'” and a table polariscope, read: “Tisley's Pendulum Apparatus, for drawing Lissajous figures (graphic drawings of the Musical Intervals) on card or on blackened glass; with Optical Arrangement for projecting them on the screen in the process of formation. (Most attractive for Class Demonstration) $£ 1414$ s.' Nature (London) 16, vii (3 May 1877). Two weeks later the company now offered “'Tisley's Harmonograph, For drawing Lissajous' and Meide's figures (graphic drawing of Harmonic Vibrations) on card or on blackened glass - most attractive for Class Demonstration-from $£ 310$ s to $£ 21$.', Nature (London) 16, xxii (17 May 1877). This also seems to be the first use of the term, "harmonograph," that I have been able to find. Its use here predates the first reference to the term cited in The Oxford English Dictionary by nearly two years. The Oxford English Dictionary (Clarendon, Oxford, 1989), Vol. VI, 2nd ed., p. 1125. The definition given there is: "An instrument for tracing curves representing sonorous vibrations.", On 31 January 1878 "S. C. Tisley \& Co." advertised this apparatus for the last time. Nature (London) 17, cx (31 January 1878). The following week it was replaced by "The Phoneidoscope, An Instrument for Observing the Colour-Figures of Liquid Films Under the Action of Sonorous Vibrations,' Nature (London) 17, cxviii (7 February 1878). Under the name, 'Tisley \& Spiller,' the firm published an advertisement for the last time on August 23, 1877: Nature (London) 16, cliii (23 August 1877). The following week it was listed as "S. C. Tisley \& Co., Opticians," Nature (London) 16, clxiv (30 August 1877).

${ }^{32}$ Queen's new form of Tisley's compound,' J. Franklin Inst. 108, 268-271 (October, 1879). This design seems to include a gas light source. A description of this design, its use, and an identical picture is included in J. A. Zahm, Sound and Music (A. C. McClurg, Chicago, 1892), pp. 408-411; this is the source of Fig. 5.

${ }^{33}$ Nature (London) 17, 394-395 (14 March 1878). The firm seems to have continued until 1884 when "S. C. Tisley \& Co., Manufacturing Opticians and Scientific Instrument Makers"' announced that: "Messrs. S. C. Tisley $\&$ Co. have great pleasure in informing Scientific Gentlemen that they have made arrangements with Mr. J. W. GAMMAGE ... to take the Management of the above business.' Nature (London) 29, cxcviii (17 April 1884).

${ }^{34}$ J. H. Pepper, Cyclopaedic Science Simplified (Frederick Warne, London, 1877), 4th ed., pp. 562-565. This edition is the first to discuss and describe Tisley's apparatus. The diagram of the apparatus (p. 563) is the same as that printed in Engineering, Ref. 31, and in Greenslade, Ref. 19, p. 257.

${ }^{35}$ Gaston Tissandier, Popular Scientific Recreations in Natural Philosophy, Astronomy, Geology, Chemistry, Etc. (Ward, Lock, and Co., London, 1883), p. 175.

${ }^{36}$ Reference 35 , p. 176.

${ }^{37}$ I. Bernard Cohen, "Lissajous figures,' J. Acoust. Soc. Am. 17, 228-230 (January, 1946). His diagram is essentially identical to that provided by Tissandier.

${ }^{38}$ Reference 37 , p. 228 . Greenslade, who has studied and photographed this apparatus, notes that ".. the weight of the second pendulum can be raised at a steady rate by what I think is a clockwork mechanism. Furthermore, the rotating table provides two more SHMs parallel to the original two, since a circle is a Lissajous figure.' Personal correspondence, 13 March 2000. See also Ref. 19, p. 258.

${ }^{39}$ Herbert C. Newton, "Simple Harmonographs," Ref. 17, pp. 4-8. This is 
the same as the diagram reproduced by Greenslade, Ref. 19, p. 257. It also illustrates the discussion of the harmonograph (attributed to Tisley and Tissandier) in Joseph Frick, Dr. J. Fricks Physikalische Technik;..., Erster Band, Zweite Abteilung (Friedrich Bieweg und Sohn, Braunschweig, 1905), 7th ed., p. 1322. An illustration of the same apparatus, on display in the Science Museum, London, may be found in John van Riemsdijk and Paul Sharp, In the Science Museum (Her Majesty's Stationery Office, London, 1968), pp. 77-78.

${ }^{40}$ Reference 17, "Descriptive and Practical Details as to Harmonographs,", pp. 39-50. The "Sympalmograph" appeared in the following announcement in Nature (London) 16, 691 (21 June 1877):

THE SYMPALMOGRAPH. A NEW PENDULUM APPARATUS FOR DRAWING LISSAJOUS SOUND CURVES. With this Apparatus the relations of Sounds to each other are shown graphically. The curves are of great beauty and variety; they may be applied to decorative purposes. Price of the Apparatus complete, in Case, $£ 3$ 10s. 0d. A Pamphlet on the Sympalmograph and Lissajous Curves, with Specimen and Diagrams, sent for Seven Stamps. JOHN BROWNING, OPTICAL AND PHYSICAL INSTRUMENT MAKER TO THE ROYAL OBSERVATORY, ETC. 63 STRAND, W.C., LONDON.

I have been unable to obtain a copy of this pamphlet. Some years later, Benham wrote a thorough description for the construction of a sympalmograph by the home craftsman in Charles E. Benham, "The Sympalmograph,' Engineering 26, 127 (26 July 1895). This article is the source of the definition of the term in The Oxford English Dictionary (Clarendon, Oxford, 1989), Vol. XVII, 2nd ed., p. 450. The definition given is: “ ‘.. an apparatus for exhibiting the combination of vibrations, consisting of a double pendulum the two parts of which can be caused to vibrate in different directions and at varying rates, with a style attached so as to trace the resulting curves on a prepared surface.',

${ }^{41}$ Reference 17 , pp. 51-61.

${ }^{42}$ Nature (London) 49, 498-499 (22 March 1894).

${ }^{43}$ Archibald Williams, "The harmonograph,' Pearson's Magazine [7], 443445 (April, 1902).

${ }^{44}$ The Oxford English Dictionary (Clarendon, Oxford, 1989), Vol. VI, 2nd ed., p. 1125. The definition given is: "A figure or curve drawn by a harmonograph.',

${ }^{45}$ Charles E. Benham, "'Miniature harmonographs,' Knowledge, new series 3, 452-454 (June, 1906). For many years Benham (1860-1929) was editor of the Essex County Standard, Colchester. He was a prolific writer on a variety of subjects including many scientific topics. A brief biographical sketch is in "Obituary: Mr. C[harles] E[dwin] Benham,', The Times (London), 3 April 1929, p. 17.

${ }^{46}$ Reference 17 , pp. 61-79.

${ }^{47} J$ oseph Goold, "Vibration-Figures: Their Production \& Constitution in Nature and in the Workshop,' Ref. 17, pp. 97-159 plus plates. Benham's "Miniature Twin Elliptic Pendulums"' were available from Newton and Co. for $£ 2$ 15s; Goold's “Twin Elliptic Pendulum”, for $£ 33 \mathrm{~s}$.

${ }^{48}$ Reference 35 , pp. 177-179.

${ }^{49}$ Rev. John Andrew, "The Pendulograph,' New Sci. Rev. 1, 166-178 (1895). Andrew is the source of the definition in The Oxford English Dictionary (Clarendon, Oxford, 1989), Vol. XI, 2nd ed., p. 469.

${ }^{50}$ S. J. M[ichael] J. Hoferer, 'Quadruple compound harmonic motion,' Sci. Am. 80, 200-201 (1 April 1899). This paper was reprinted in George M. Hopkins, Experimental Science: Elementary Practical and Experimental Physics (Munn, New York, 1911), Vol. II, 27th ed., pp. 420-428. An abstract of a four pendulum apparatus had been published earlier in S. C. Tisley, "A four-pendulum apparatus,"' Rep. Br. Assn. Adv. Sci. 44, 44-45 (1874). I have found nothing further on this design.

${ }^{51}$ H. Martyn Cundy and A. P. Rollett, Mathematical Models (Clarendon, Oxford, 1961), 2nd ed., pp. 248-251.

${ }^{52}$ Reference 51, pp. 242-245; 246-248

${ }^{53}$ Reference 22 .

${ }^{54}$ A. D. Bulman, Model Making for Young Physicists (John Murray, London, 1963), pp. 42-46; reprinted as Model-Making for Physicists (Crowell, New York, 1968), pp. 86-94.

${ }^{55}$ C. L. Stong, "The amateur scientist,' Sci. Am. 212, 128-130 (May 1965).

${ }^{56}$ R. L. Doan, "The harmonograph as a project in high school physics," Sch. Sci. Math. 23, 450-455 (May, 1923). A similar, but slightly more elaborate design, was listed in 1949 Catalog: Scientific Apparatus, Chemi- cals, and Supplies (W. M. Welch Scientific Company, Chicago, 1949), p. 56; Cat. No. 834, $\$ 35.00$.

${ }^{57}$ E. G. Plasterer, "A demonstration apparatus for the composition of two simple harmonic curves,' Sch. Sci. Math. 34, 424-426 (April, 1934).

${ }^{58}$ Wallace A. Hilton, 'Lissajous figures,', Sch. Sci. Math. 57, 7-8 (January, 1957).

${ }^{59}$ Leonard Rose Ingersoll, A Laboratory Manual of Experiments in Physics (McGraw-Hill, New York, 1925), p. 164. Ingersoll refers to Duff, who provides examples of the curves to be drawn and who refers to the Y-suspended pendulum. A. Wilber Duff, ed., A Text-Book of Physics (Blakiston's Son, Philadelphia, 1921), 5th ed., pp. 179-181.

${ }^{60}$ Leonard Rose Ingersoll and Miles Jay Martin, A Laboratory Manual of Experiments in Physics (McGraw-Hill, New York, 1942), 5th ed., pp. $224-225$

${ }^{61}$ Leonard Rose Ingersoll, Miles Jay Martin, and Theodore Alton Rouse, A Laboratory Manual of Experiments in Physics (McGraw-Hill, New York, 1953), 6th ed., pp. 173-175.

${ }^{62}$ S. Tolansky, "Complex curvilinear designs from pendulums," Leonardo 2, 267-274 (1969).

${ }^{63}$ Reference 62, pp. 268-270.

${ }^{64}$ Reference 62, pp. 271-274.

${ }^{65}$ Reference 62, p. 274.

${ }^{66}$ R. H. Romer, "A double pendulum 'Art machine,',' Am. J. Phys. 38, 1116-1121 (1970)

${ }^{67}$ Reference 66, p. 1116.

${ }^{68}$ Harry F. Meiners, ed., Physics Demonstration Experiments, Mechanics and Wave Motion Vol. I (Ronald, New York, 1970), pp. 347-348.

${ }^{69}$ Robert L. Weber, ed., More Random Walks in Science (IOP, London, 1982), pp. 82-86. The title was: "The future European harmonic pendulum: Report of a working party appointed by The Arts Research Council.", This was reprinted from Orbit, Journal of the Rutherford High Energy Laboratory, Didcot, England, December, 1964, p. 8.

${ }^{70} \mathrm{~A}$ detailed account of early scientific instruments at Harvard was given some years ago by I. Bernard Cohen, Some Early Tools of American Science (Harvard U.P., Cambridge, MA, 1950; Russell \& Russell, New York, 1967). This is to be supplemented by David P. Wheatland, The Apparatus of Science at Harvard: 1765-1800 (Harvard U.P., Cambridge, MA, 1968).

${ }^{71}$ While the harmonograph is not specifically addressed, an introduction to some of the problems that might be encountered in its analysis may be found in Arnold Sommerfeld, Mechanics Lectures on Theoretical Physics Vol. 1 (Academic, New York, 1952). See particularly his discussion of the "simple pendulum," pp. 87-90; the "compound pendulum,' pp. 91-93; and the "double pendulum," pp. 111-114 and 195-196. The "doubleelliptic" harmonograph is a form of a double pendulum. However, Sommerfeld's analysis deals only with the specific case in which a large (nearly) point mass is suspended from a support by a massless string, and a much smaller mass is suspended from this mass by a string of nearly equal length.

${ }^{72}$ Reference 12 , p. 298.

${ }^{73}$ Giorgio Tabarroni, 'Righi, Augusto,' Dictionary of Scientific Biography (Scribner's, New York, 1970), Vol. 11, pp. 460-461.

${ }^{74}$ Augusto Righi, "Sulla composizione dei moti vibratori,', Nuovo Cimento 9, 160-200 (1873); 10, 19-37 (1873); 10, 125-137 (1873).

${ }^{75}$ Nature (London) $\mathbf{5 8}, 488-489$ (15 September 1898). This summary seems to be based on a report to the Bolgona Academy of Sciences and published in Augusto Righi, "Appar. per la composiz. d. oscillaz. di 2 pendoli,", Memorie della Accademia delle Scienze dell' Instituto di Bologna 6, 12 pp. (1897). I have not seen this paper.

${ }^{76}$ Reference 16 , p. 422.

${ }^{77}$ J. H. Poynting and J. J. Thomson, A Text-Book of Physics: Sound (Charles Griffin, London, 1927), 9th ed., pp. 74-79.

${ }^{78}$ Reference 77, p. 79

${ }^{79}$ Arthur Taber Jones, Sound: A Textbook (Van Nostrand, New York, 1937), p. 130

${ }^{80}$ Reference 62, p. 267.

${ }^{81}$ J. Dennis Lawrence, A Catalog of Special Curves (Dover, New York, 1972), p. 178.

${ }^{82}$ A. K. Dewdney, 'CComputer recreations,'” Sci. Am. 258, 120 (May, 1988).

${ }^{83}$ P. H. Sydenham, Measuring Instruments: Tools of Knowledge and Control (Peter Peregrinus, Stevenage, UK, 1979), p. 78.

${ }^{84}$ Reference 19 , p. 256.

${ }^{85}$ Crowell, Ref. 13

${ }^{86}$ M. J. Lissajous, "Note sur un appareil simple qui permet de constater 
l'interférence des ondes sonores,', C. R. Acad. Sci. 40, 133-135 (1855); "Note sur un moyen nouveau de mettre en evidence le mouvement vibratoire des corps,' 41, 93-95 (1855); “'Note sur un moyen nouveau à l'étude des mouvements vibratoires,'” 41, 814-817 (1855); “'Note sur un cas particulier de stéréoscopie fourni par l'étude optique des mouvements vibratoires.-Tracé graphique des courbes auxquelles cette étude conduit,' 43, 973-976 (1855); “Mémoire sur l'étude optique des mouvements vibratoires," 44, 727 (1857); "Note sur les vibrations transversales des lames élastiques,'” 46, 846-848 (1858).

${ }^{87}$ J. Lissajous, "Mémoire sur l'étude optique des mouvements vibratoires,', Ann. Chim. Phys. Ser. 3 51, 147-231 (1857). An excerpt of this paper, translated by Harry B. Miller, may be found in: J. Lissajous, "Memoir on the optical study of vibratory motion," in Acoustical Measurements: Methods and Instrumentation, edited by Harry B. Miller (Hutchinson Ross, Stroudsburg, PA, 1982), pp. 6-23.

${ }^{88}$ John Tyndall, 'On M. Lissajous' acoustic experiments,' Proc. R. Inst. 2, 441-443 (1857). Tyndall provided a clear summary of the experiments performed by Lissajous in the lecture.

${ }^{89}$ The award citation is printed in: "'Prix Lacaze, Physique,' C. R. Acad. Sci. 79, 1607-1610 (1874). A biography of Lissajous (1822-1880) may be found in Sigalia Dostrovsky, 'Lissajous, Jules Antoine,' Dictionary of Scientific Biography (Scribner's, New York, 1970), Vol. 8, pp. 398-399.
${ }^{90}$ F. Melde, "Uber einen neuen Apparat zur Darstellung von Schwingungscurven," Ann. Phys. Chem. 115, 117-125 (1862).

${ }^{91}$ Ferdinand Lippich, "Uber die transversalen Schwingungen belaster Stäbe,' Denkschriften der Kaiserlichen Akademie der Wissenschaften 21, 130-173 (1862)

${ }^{92}$ Reference 74.

${ }^{93}$ J. W. Strutt and Lord Rayleigh, The Theory of Sound (Macmillan, London, 1894; Dover, New York, 1945), Vol. I, Rev. ed., pp. 26-35.

${ }^{94}$ A. P. French, Vibrations and Waves (Norton, New York, 1971), pp. 2939.

${ }^{95}$ Edward F. Fahy and Frank G. Karioris, "Geometrical and graphical representations of Lissajous figures,'” Am. J. Phys. 20, 121-123 (1952).

${ }^{96}$ Frank G. Karioris, "Projection sine-sine grid and Lissajous figures," Phys. Teach. 13, 294-296 (May, 1975).

${ }^{97}$ B. A. Smith, 'Lissajous' figures,' Phys. Educ. 16, 38-44 (January, 1981).

${ }^{98} \mathrm{Mu}$-Shiang $\mathrm{Wu}$ and W. H. Tsai, "Corrections for Lissajous figures in books,', Am. J. Phys. 52, 657-658 (1984).

${ }^{99}$ Thomas B. Greenslade, Jr., 'All about Lissajous figures,' Phys. Teach. 32, 364-370 (September, 1993).

${ }^{100}$ E. Y. C. Tong, 'Lissajous figures,'” Phys. Teach. 35, 491-493 (November, 1997).

\section{PRIORITY}

Ostwald's main line of argument was that an understanding of the etiology of scientific problems constitutes the most effective means toward a sound scientific education. Moreover, insight into the vagaries of history, into the inevitable hostility encountered by new theories, justified primarily by the new theory's crass contradiction with established views, was invariably and paradoxically followed by the claim that the new ideas are in fact old, and that forerunners exist to most any innovation. Ostwald's critical attitude toward such "knee-jerk" hostility to new ideas was by no means uncommon. A similar critique was later leveled by Whitehead, who remarked that "Everything of importance has been said before by somebody who did not discover it" and that "there is a considerable difference between a vague awareness of a particular problem and systematic research into it."

Diane Kormos Barkan, Walther Nernst and the Transition to Modern Physical Science (Cambridge U.P., New York, 1999), p. 46. 